Article

\title{
The Application of Self-Assembled of Meso-2,3- Dimercaptosuccinic Acid-Polydopamine-Zinc Oxide for Trace Cadmium Analysis
}

\author{
Min Lu ${ }^{1,2}$, Xu Zhang ${ }^{2, *}$ and Nuo Chen ${ }^{3}$ \\ 1 Hubei Harmful Solid Waste Management Center, Wuhan 430072, China; minluhubei@gmail.com \\ 2 Department of Environmental Science, Wuhan University, Wuhan 430079, China \\ 3 Construction \& Management Bureau of North Hubei Water Transfer Project, Wuhan 430062, China; \\ chennuo.19890506@163.com \\ * Correspondence: xuzhangwhu@gmail.com; Tel.: +86-276-877-8381
}

Received: 24 July 2019; Accepted: 4 February 2020; Published: 3 April 2020

Featured Application: A novel meso-2,3-dimercaptosuccinic acid and polydopamine modified zinc oxide were synthesized through a layer-by-layer self-assembly process, and the hybrid $\mathrm{ZnO}$ was suitable for enriching trace cadmium in natural water samples.

\begin{abstract}
Nanomaterials have been applied in the analysis of trace contaminants in aquatic samples; however, the adsorption affinity of heavy metal ions to metallic oxide nanoparticles is low. Meso-2,3-dimercaptosuccinic acid-polydopamine-zinc oxide (DMSA/PDA/ZnO) was synthesized through a facile self-assembly process for enhancing the adsorption capacity of $\mathrm{ZnO}$ to cadmium cation $(\mathrm{Cd}(\mathrm{II}))$. A method for the analysis of trace $\mathrm{Cd}(\mathrm{II})$ in water samples was developed while using dimercaptosuccinic acid/Polydopamine/zinc oxide (DMSA/PDA/ZnO) as an adsorbent and atomic absorption spectrometry (AAS) as a means of determination. The results demonstrate that the adsorption ratio of DMSA-PDA-ZnO to $1 \mathrm{mg} / \mathrm{L} \mathrm{Cd}(\mathrm{II})$ is around $95 \%$ at $\mathrm{pH} 6.0-8.0$ with a contact time of $31 \mathrm{~h}$, and the enrichment rate can be more than $98 \%$ with the dosage of DMSA-PDA-ZnO exceeding $1.0 \mathrm{~g} / \mathrm{L}$. The adsorption isotherm of $\mathrm{Cd}(\mathrm{II})$ to DMSA/PDA/ZnO fits the Langmuir equation well, and the saturated adsorption of DMSA-PDA-ZnO to Cd(II) is $28.5 \mathrm{mg} / \mathrm{g}$. The detection limit $(3 \sigma)$ of this method is $0.1 \mu \mathrm{g} / \mathrm{L}$, with a relative standard deviation of $1 \%$. Additionally, this method presents satisfactory performance with a recovery rate of $86-90 \%$ when applied to the detection of $\mathrm{Cd}(\mathrm{II})$ in environmental water samples.
\end{abstract}

Keywords: cadmium; dimercaptosuccinic acid; polydopamine; $\mathrm{ZnO}$

\section{Introduction}

The measurement of aquatic chemical substrates is important for research on water quality assessment, human health, and water pollution control. Among the chemical substrates, cadmium (Cd) is a well-known toxic and persistent pollutant that can cause both short-term and long-term health effects [1,2]. Besides foods, drinking water is the major source for human exposure to Cd(II), and the guideline value for $\mathrm{Cd}$ in drinking water is $3 \mu \mathrm{g} / \mathrm{L}$, as set by the World Health Organization (WHO) [3]. The concentrations of $\mathrm{Cd}$ in unpolluted water are low, and the reported concentrations of Cd were at (or below) the $\mu \mathrm{g} / \mathrm{L}$ level $[4,5]$. High values of tens of $\mu \mathrm{g} / \mathrm{L}$ were also reported in some water samples [6]. A low concentration of $\mathrm{Cd}$ in natural water and drinking water samples requires high-sensitivity analytical methods for the precise concentration measurement. Graphite furnace atomic absorption spectrometry (GFAAS) [7], flame furnace atomic absorption spectrometry (FAAS) [8], colorimetric determination with dithizone $[9,10]$, inductively coupled argon plasma mass spectrometry 
(ICP-MS) [11], and inductively coupled plasma atomic emission spectrometry (ICP-AES) [12] were applied to determine the trace $\mathrm{Cd}$ in water samples.

However, the methods were not valid for the direct analysis of some samples with extremely low Cd concentrations, with the exception of ICP-MS. For example, the limit of detection (LOD) for Cd(II) by GFAAS was $3 \mu \mathrm{g} / \mathrm{L}$, which was larger than the concentrations found in water samples. Therefore, preconcentration is necessary during analytical procedures [5,13]. Adsorbents, like chelating resins [14], mesoporous sorbent [15], etc., have been investigated for the preconcentration of $\mathrm{Cd}(\mathrm{II})$ in water samples. However, a desorption process was needed after preconcentration with these solid adsorbents, which made the analytic process complicated, time-consuming, and the recovery ratio was not good because of the incomplete desorption. Therefore, the development of new preconcentration methods with high sensitivity and easy operation processes for the analysis of ultra-trace $\mathrm{Cd}$ is necessary. For instance, slurry sampling was applied to analyze the adsorbate with adsorbents to avoid the desorption process. However, stabilizers, like agar and surfactant, are usually needed, and success of the slurry sampling technique depends on many parameters, such as the sample particle size, stabilizer ratio, etc. The addition of stabilizers could increase the background value of the matrix to some extent [16].

Differently from other inert metallic oxide nanomaterials, $\mathrm{ZnO}$ is soluble in acidic or alkaline solutions. Namely, the pre-concentrated solutes can be directly redissolved for its concentration analysis. However, like other metallic oxide nanomaterials, $\mathrm{ZnO}$ has low adsorption capacity to $\mathrm{Cd}(\mathrm{II})$. The modification of $\mathrm{ZnO}$ is needed to increase the binding affinity. Polydopamine (PDA) deposition has been successfully applied in the modification of metallic oxide $[17,18]$, silicon dioxide [19], carbon-based nanomaterials [20], hydrophobic polymer [21], and other material surfaces. PDA coated adsorbents have high adsorption capacity of Cd(II) and other heavy metal ions [22,23]. For instance, the adsorption capacity of Cd(II) onto PDA modified meso-structured silica is $107 \mathrm{mg} / \mathrm{g}$ [22]. Thiol has a higher chelating ability with Cd(II) when compared to hydroxyl and amino functional groups $[24,25]$. Dimercaptosuccinic acid (DMSA) is a well-known chelating agent for $\mathrm{Cd}(\mathrm{II})$ that has been used for $\mathrm{Cd}(\mathrm{II})$ antidote [26]. For instance, $\mathrm{Cd}$ (II) could be chelated by DMSA in aqueous solutions at $\mathrm{pH}$ 7.4 [27]. Further, DMSA can react with PDA through $-\mathrm{COOH}$ and $-\mathrm{NH}_{2}$. Therefore, DMSA/PDA/ZnO can have the advantages of high adsorption capacity of $\mathrm{Cd}(\mathrm{II})$ and being soluble in acidic solutions, and it can be a novel candidate for ultra-trace Cd(II) preconcentration and analysis.

The purpose of this study was to synthesize DMSA/PDA/ZnO and reveal its performance in enriching ultra-trace $\mathrm{Cd}(\mathrm{II})$ and determining the concentration of $\mathrm{Cd}(\mathrm{II})$ in the samples with dissolved DMSA/PDA/ZnO by FAAS with nickel nitrate as a matrix modifier. The adsorption kinetics and isotherm of $\mathrm{Cd}(\mathrm{II})$ on DMSA/PDA/ZnO was investigated and the preliminary mechanism for the adsorption was proposed. The experimental parameters for the preconcentration and analysis of $\mathrm{Cd}(\mathrm{II})$ were optimized in this study. The proposed method was applied to a standard sample, natural surface water with satisfactory results. The omission of complicated desorption processes is the advantage of using DMSA/PDA/ZnO as the adsorbent coupled with FAAS.

\section{Materials and Methods}

\subsection{Materials}

Analytical grade DMSA, dopamine hydrochloride, zinc acetate dihydrate, and potassium hydroxide (KOH) were purchased from Sinopharm Group Co. LTD (Shanghai, China), and used as received. In addition, $1000 \mu \mathrm{g} / \mathrm{mL}$ Cd(II) standard calibration solution (No. GSB04-1721-2004) was a commercial product of Institution for the Environmental Reference Materials Ministry of Environmental Protection (Beijing, China). $\mathrm{HCl}(5 \%, v / v)$ was used to dissolve DMSA/PDA/ZnO. Ultrapure water was used to prepare all of the working solutions. 


\subsection{Synthesis of $D M S A / P D A / Z n O$}

Synthesis of ZnO. In a typical synthesis process, $14.75 \mathrm{~g}$ of Zinc acetate dehydrate was added to $60 \mathrm{~mL}$ of methanol (solution A), and $7.4 \mathrm{~g} \mathrm{KOH}$ was added to $32 \mathrm{~mL}$ of methanol (solution B). Subsequently, solution B was dropwise added to solution A under vigorous stirring ( $250 \mathrm{rpm})$. The resulting solution was heated to $60^{\circ} \mathrm{C}$ and kept for $72 \mathrm{~h}$, and the reaction was then cooled to room temperature. The obtained $\mathrm{ZnO}$ was washed with methanol six times and then dried under vacuum at $40^{\circ} \mathrm{C}$ for $6 \mathrm{~h}$.

Synthesis of PDA coating ZnO (PDA/ZnO). Quantities of $2 \mathrm{~g}$ of dopamine and $5 \mathrm{~g} \mathrm{ZnO}$ were added to $1000 \mathrm{~mL}$ oxygen-free Tris buffer $(0.1 \mathrm{M}, \mathrm{pH} 8.5)$, and stirred at $250 \mathrm{rpm}$ in the dark for $12 \mathrm{~h}$. Argon was bubbled to the solution through reaction. Afterwards, crude PDA/ZnO was recovered by centrifugation ( $6000 \mathrm{r} / \mathrm{min}$., $25 \mathrm{~min}$.). Crude $\mathrm{PDA} / \mathrm{ZnO}$ was washed by ultrapure water six times and then dried under vacuum at $40{ }^{\circ} \mathrm{C}$ for $6 \mathrm{~h}$.

Synthesis of DMSA/PDA/ZnO. A quantity of $0.25 \mathrm{~g}$ DMSA was added to $500 \mathrm{~mL}$ oxygen-free Tris buffer ( $0.1 \mathrm{M}, \mathrm{pH} 8.5)$, and stirred at $250 \mathrm{rpm}$ in the dark for $0.5 \mathrm{~h}$, followed by the addition of $5 \mathrm{~g}$ $\mathrm{PDA} / \mathrm{ZnO}$. Then, the resulting solution was stirred at $250 \mathrm{rpm}$ in the dark for $12 \mathrm{~h}$. Argon was bubbled to the solution through reaction. Crude DMSA/PDA/ZnO was recovered by centrifugation $(6000 \mathrm{r} / \mathrm{min}$., $25 \mathrm{~min}$.), and then washed by ultrapure water six times and then dried under vacuum at $40^{\circ} \mathrm{C}$ for $6 \mathrm{~h}$.

\subsection{Characterization of $D M S A / P D A / Z n O$}

The X-ray powder diffraction (XRD) spectra of $\mathrm{ZnO}, \mathrm{PDA} / \mathrm{ZnO}$, and DMSA/PDA/ZnO were measured with a Dmax-rA powder diffractometer (Rigaku, Japan), with $\mathrm{Cu} K \alpha$ as a radiation source at a scanning rate of $2^{\circ} / \mathrm{min}$. Contents of elements $(\mathrm{C}, \mathrm{H}, \mathrm{N}$, and $\mathrm{S})$ in these materials were quantified by an elemental analyzer (Vario Cube; Elementar, Langenselbold, Germany). Scanning electron micrograph (SEM) was taken with a FEI-QUANTA 200 microscope, and the transmission electron microscopy (TEM) images were recorded on a JEOL JEM 2010HT microscope (Japan Electronics, Tokyo, Japan) at an accelerating voltage of $200 \mathrm{kV}$. The FT-IR spectra of sample pellets with $\mathrm{KBr}$ were recorded on a Nicolet 5700 Fourier transform infrared (FTIR) spectrometer (Thermo Electron Corporation, Waltham,

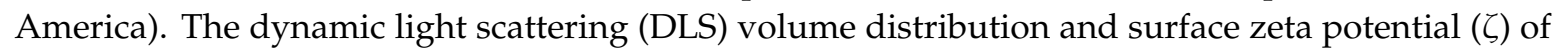
$\mathrm{ZnO}, \mathrm{PDA} / \mathrm{ZnO}$, and DMSA/PDA/ZnO $\left(0.1 \mathrm{~g} / \mathrm{L} \mathrm{H}_{2} \mathrm{O}\right.$ suspension) was measured with a Zetasizer nano device (Malvern, UK).

\subsection{Adsorption of $C d(I I)$ on $D M S A / P D A / Z n O$}

$250 \mathrm{~mL}$ working solution containing $1-40 \mathrm{mg} / \mathrm{L} \mathrm{Cd}(\mathrm{II})$ was added to a flask, followed by the addition of a certain amount of $\mathrm{ZnO}$ related adsorbent $(0.1-1.0 \mathrm{~g} / \mathrm{L})$. Afterwards, the solution $\mathrm{pH}$ was adjusted (3.0-9.0) and the resulting solution was shaken at $25^{\circ} \mathrm{C}$. Solution samples of $10 \mathrm{~mL}$ were withdrawn at different time intervals, and then centrifuged at $7000 \mathrm{r} / \mathrm{min}$. for $20 \mathrm{~min}$. A certain amount of supernatant was transferred into a volumetric flask and $0.5 \mathrm{~mL} \mathrm{HCl}$ was added, and the solution was diluted to $10 \mathrm{~mL}$ with ultrapure water.

The Cd(II) concentration was then determined by on a Hitachi Z-5000 Polarized Zeeman Atomic Absorption Spectrophotometer (Hitachi High-Technologies Corporation, Tokyo, Japan). The initial concentration and concentration at different adsorption times were expressed as $c_{0}$ and $c_{\mathrm{t}}$, respectively. $c_{\mathrm{e}}$ and $q_{\mathrm{e}}$ is the concentration of $\mathrm{Cd}(\mathrm{II})$ in the water phase and adsorbent after reaching adsorption equilibrium, respectively. $c_{\mathrm{e}}$ and $q_{\mathrm{e}}$ that were obtained from different $\mathrm{Cd}(\mathrm{II})$ initial concentrations $(1-40 \mathrm{mg} / \mathrm{L})$ were used to investigate the adsorption isotherm.

\subsection{Protocol for Preconcentration of Cd(II) with of DMSA/PDA/ZnO}

A $100 \mathrm{~mL}$ water sample was added to a flask containing $1.0 \mathrm{~g} / \mathrm{L}$ DMSA/PDA/ZnO, and then the solution was shaken at $25^{\circ} \mathrm{C}$ for $3 \mathrm{~h}$. After that, the dispersion was filtrated while using a $0.45 \mu \mathrm{m}$ 
membrane. The membrane was washed and diluted to $10 \mathrm{~mL}$ with $5 \% \mathrm{HCl}$. FAAS directly determined the concentration of $\mathrm{Cd}(\mathrm{II})$ in the solution mentioned.

\subsection{Data Analysis}

The adsorption ratio $(R, \%)$ was calculated by Equation (1),

$$
R=\left(1-\frac{c_{\mathrm{e}}}{c_{0}}\right) \times 100 \%
$$

The adsorption isotherm was fitted by Equations (2) and (3),

$$
q_{\mathrm{e}}=\frac{q_{\max } \times K_{L} \times c_{\mathrm{e}}}{1+K_{L} \times c_{\mathrm{e}}}
$$

where $q_{\mathrm{e}}$ and $q_{\max }(\mathrm{mg} / \mathrm{g})$ are the equilibrium and maximum adsorption of $\mathrm{Cd}(\mathrm{II})$ on DMSA/PDA/ZnO, and $K_{\mathrm{L}}(\mathrm{L} / \mathrm{mg})$ is the Langmuir adsorption constant.

$$
q_{\mathrm{e}}=K_{F} \times c_{\mathrm{e}}^{1 / n}
$$

$K_{F}$ and $1 / n$ represent the Freundlich adsorption constant and the unitless linearity parameter, respectively.

Limit of detection (LOD) was the calculated concentration to a signal of three times standard deviation of blank sample.

\section{Results}

\subsection{Structural Characterization of $\mathrm{ZnO}, \mathrm{DPOA} / \mathrm{ZnO}$, and $\mathrm{DMSA} / \mathrm{DPOA} / \mathrm{ZnO}$}

Figure 1 presents the $\mathrm{XRD}$ patterns of $\mathrm{ZnO}, \mathrm{DPOA} / \mathrm{ZnO}$, and DMSA/DPOA/ZnO for $2 \theta$ ranging from 10 to $80^{\circ}$. All the three $\mathrm{ZnO}$ relevant materials exhibited the same XRD pattern, indicating the structure did not change during the coating process. Peaks that were observed at 31.7, 34.4, 36.2, $47.5,56.5,62.8,66.3,67.9$, and $69.0^{\circ}$ were indexed to hexagonal wurtzite (ZnO; JCPDS Data Card no. 36-1451). By using the Williamson-Hall method [28], it was found that the obtained average crystallite size of $\mathrm{ZnO}$ was 23, 23, and $25 \mathrm{~nm}$ for bare $\mathrm{ZnO}, \mathrm{PDA} / \mathrm{ZnO}$, and DMSA/PDA/ZnO, respectively. The corresponding strains are $0.88 \%, 0.88 \%$, and $1.01 \%$.

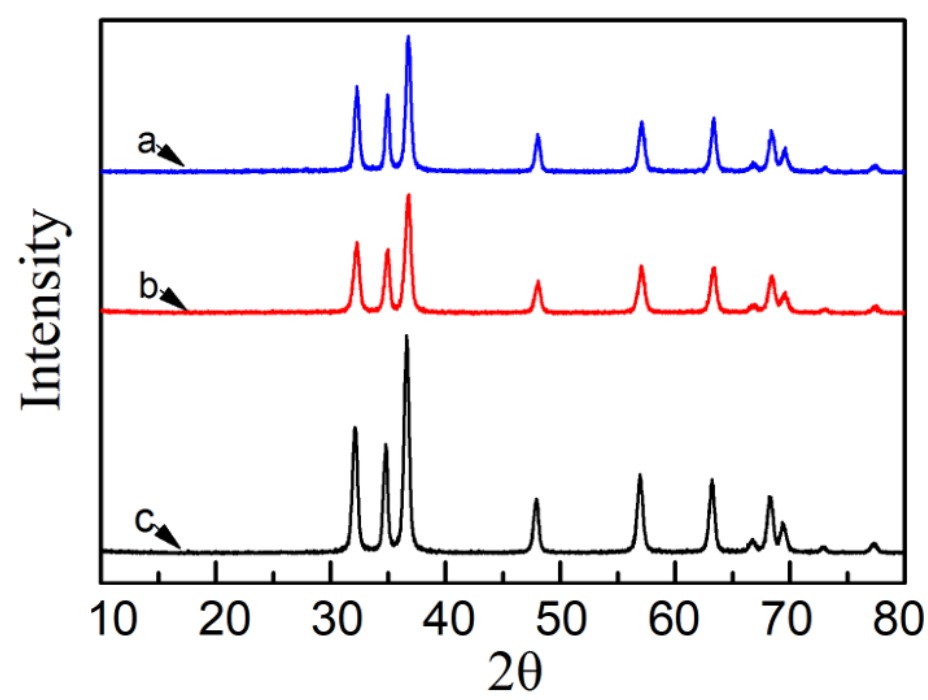

Figure 1. XRD spectra of (a) zinc oxide ( $\mathrm{ZnO}),(\mathbf{b})$ polydopamine/ZnO (PDA/ZnO), and (c) dimercaptosuccinic acid/Polydopamine/zinc oxide (DMSA/PDA/ZnO). 


\subsection{Morphology of $\mathrm{ZnO}, \mathrm{DPOA} / \mathrm{ZnO}$, and $\mathrm{DMSA} / \mathrm{DPOA} / \mathrm{ZnO}$}

Figures 2 and 3 present SEM and TEM images, respectively. ZnO exhibited as small particles, and the size became larger after the coating of PDA and DMSA. DMSA/PDA/ZnO adheres to each other when compared with $\mathrm{ZnO}$ and $\mathrm{PDA} / \mathrm{ZnO}$.

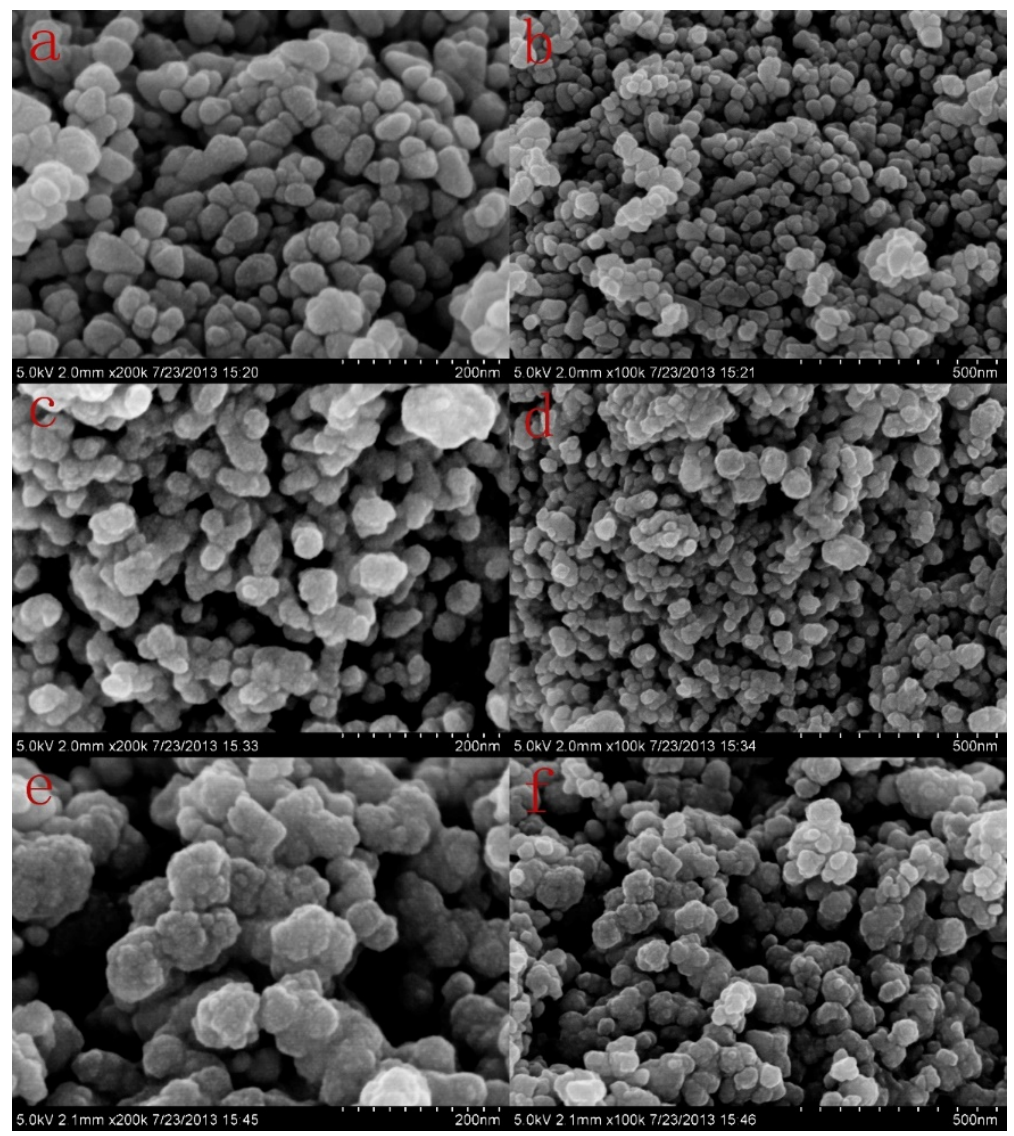

Figure 2. Scanning electron microscopy (SEM) images of $(\mathbf{a}, \mathbf{b}) \mathrm{ZnO},(\mathbf{c}, \mathbf{d}) \mathrm{PDA} / \mathrm{ZnO}$, and $(\mathbf{e}, \mathbf{f})$ DMSA/PDA/ZnO.

The $\mathrm{ZnO}$ that was used in this study has a relative wide size distribution range (16-36 nm) with the majority at 22-26 nm (Figure S1, Supplementary Materials). The size of the ZnO core was not changed after modification by PDA and DMSA. The size values from TEM analysis are close to the diameter that was estimated from XRD analysis. However, these values were smaller than their corresponding hydrodynamic diameter that was obtained from DLS analysis (Figure S2), suggesting both barely and modified $\mathrm{ZnO}$ tend to form agglomerates. When compared with the TEM images of $\mathrm{ZnO}$ (Figure 3a,b), it could be clearly observed that the outer surface of PDA/ZnO was capped by an amorphous coating, which was assigned as the attached PDA layer (Figure 3c,d). The PDA layer was approximately $12-15 \mathrm{~nm}$ in thickness. It also demonstrated that the "carbohydrate" layer became thicker after further coating with DMSA (Figure 3e,f).

The results of the TEM and SEM suggested that PDA and DMSA were both attached to the ZnO surface and that assembly behavior resulted in morphological changes of $\mathrm{ZnO}$ through the formation of the "carbohydrate" layer (Vide Infra). 


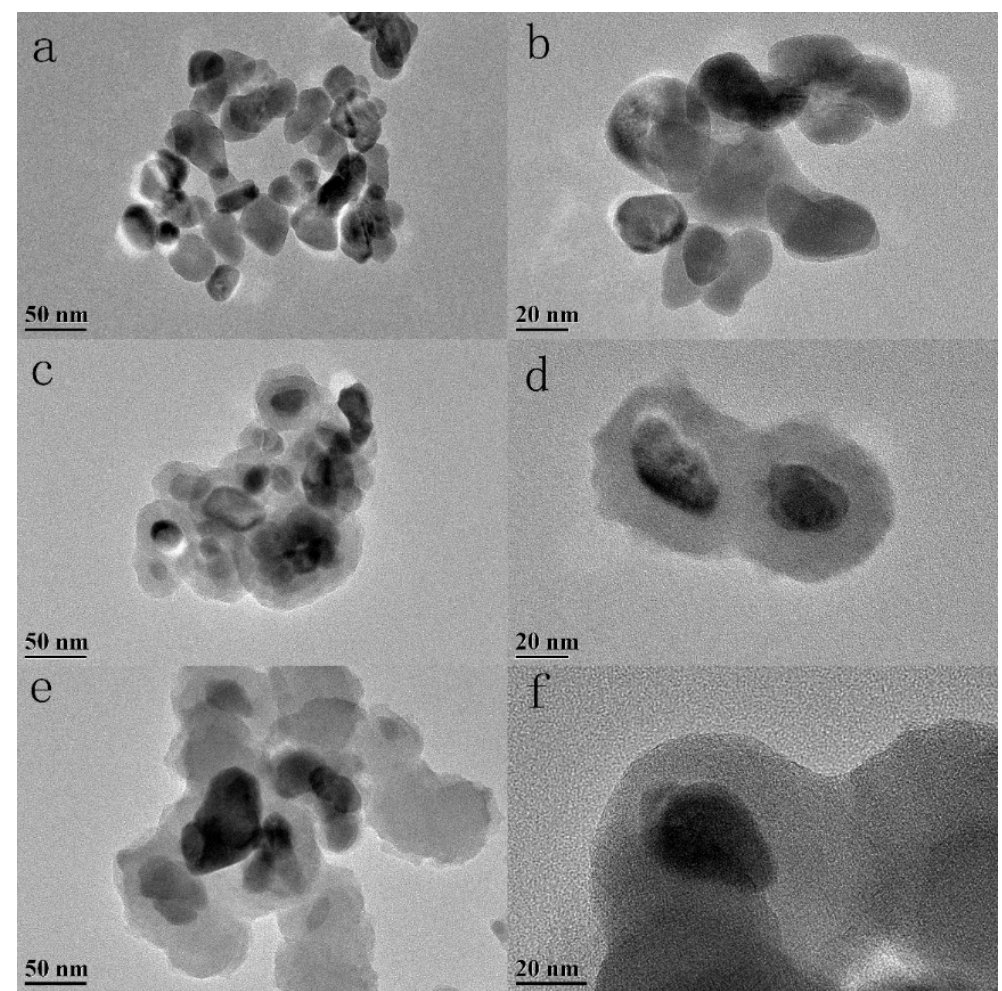

Figure 3. Transmission electron microscopy (TEM) images of $(\mathbf{a}, \mathbf{b}) \mathrm{ZnO}$, (c,d) PDA/ZnO, and (e,f) DMSA/PDA/ZnO.

\subsection{FTIR Spectra of $\mathrm{ZnO}$ and $D M S A / P D A / Z n O$}

The sharp peak around $434 \mathrm{~cm}^{-1}$ were assigned as the $\mathrm{Zn}-\mathrm{O}$ stretching bond, as shown in Figure 4 (Black line) [29]. Two narrow peaks around $1580 \mathrm{~cm}^{-1}$ and $1380 \mathrm{~cm}^{-1}$ in the FTIR spectrum of bare ZnO were attributed to deformation vibrations of the adsorbed water and the in-plane angular deformation of the surface $\mathrm{OH}$ groups, respectively. However, these two peaks might also from residues of the substrates used for $\mathrm{ZnO}$ synthesis (Section 2.2). New peaks were found in the FTIR spectrum of DMSA/PDA/ZnO, which suggested the existence of other compounds other than $\mathrm{ZnO}$. Peaks around $1604 \mathrm{~cm}^{-1}, 1272 \mathrm{~cm}^{-1}$, and $1039 \mathrm{~cm}^{-1}$ were from the vibration of attached PDA [30,31]. No peaks belonging to DMSA were obtained in FTIR spectrum of DMSA/PDA/ZnO, which might be due to its low amount (Vide Infra).

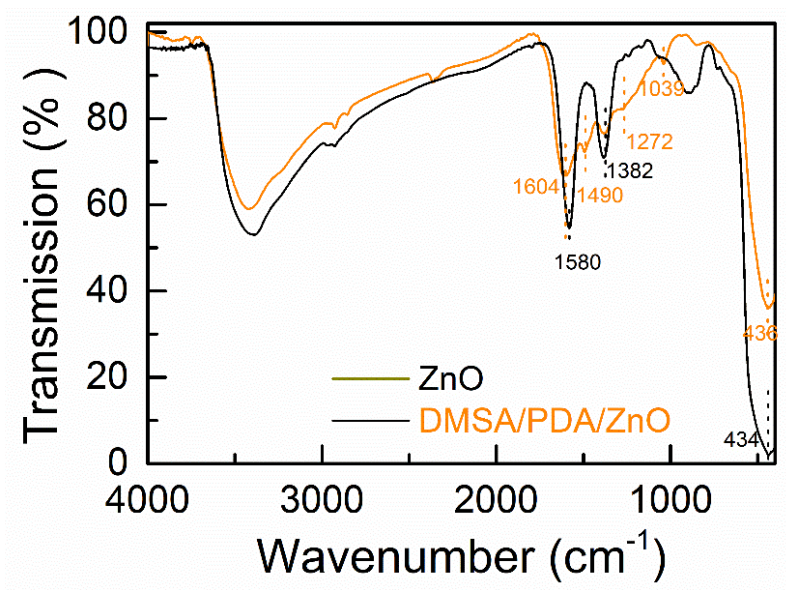

Figure 4. Fourier transform infrared (FTIR) spectra of $\mathrm{ZnO}$ and DMSA/PDA/ZnO. 


\subsection{Quantification of Attached DMSA and PDA in DMSA/PDA/ZnO}

There is little $\mathrm{C}, \mathrm{H}$, and $\mathrm{S}$ in bare $\mathrm{ZnO}$, which might be the residual of reactants after solvents wash, as listed in Table 1 (see Section 2.2). The contents of $\mathrm{C}, \mathrm{N}$, and $\mathrm{H}$ are much higher in PDA/ZnO relative to $\mathrm{ZnO}$, indicating the coating of an organic layer. The molar ratio of $\mathrm{C}: \mathrm{N}: \mathrm{H}$ is 8.1:1:10.6, which is close to the molar ratio in dopamine (8:1:11). Therefore, the attached layer was assigned as polydopamine in $\mathrm{PDA} / \mathrm{ZnO}$, and the mass content of PDA is $10.8 \%$ in PDA/ZnO. After further modification by DMSA, the content of sulphur (S) increased to $0.834 \%$ in DMSA/PDA/ZnO, which indicated the presence of DMSA. According to the ratio of molecular weight of $S$ to DMSA, the attached DMSA is approximately $2.4 \%$ in DMSA/PDA/ZnO.

Table 1. Element (C, H, N, and S) contents (\%) in $\mathrm{ZnO}, \mathrm{PDA} / \mathrm{ZnO}$, and DMSA/PDA/ZnO.

\begin{tabular}{ccccc}
\hline Element & $\mathbf{C}$ & $\mathbf{N}$ & $\mathbf{H}$ & $\mathbf{S}$ \\
\hline $\mathrm{ZnO}$ & 0.03 & 0 & 0.041 & 0.010 \\
$\mathrm{PDA} / \mathrm{ZnO}$ & 8.63 & 1.24 & 0.941 & 0.012 \\
$\mathrm{DMSA} / \mathrm{PDA} / \mathrm{ZnO}$ & 8.08 & 1.18 & 1.076 & 0.834 \\
\hline
\end{tabular}

\subsection{Adsorption of $\mathrm{Cd}(\mathrm{II})$ on $\mathrm{ZnO}, \mathrm{PDA} / \mathrm{ZnO}$, and $\mathrm{DMSA} / \mathrm{PDA} / \mathrm{ZnO}$}

Figure 5 illustrates a change in Cd(II) concentration with contact time. The bulk concentration of $\mathrm{Cd}$ (II) decreased sharply in the first $30 \mathrm{~min}$. and then gradually decreased over the next $150 \mathrm{~min}$. when DMSA/PDA/ZnO was used as adsorbent (Figure 5a). When compared with the high adsorption ratio $(R, 100 \%)$ on DMSA/PDA/ZnO, the adsorption ratio on $\mathrm{ZnO}$ and $\mathrm{PDA} / \mathrm{ZnO}$ was much lower (inset Figure 5a). The results demonstrated that the adsorption capacity of DMSA/PDA/ZnO mainly resulted from the DMSA. The adsorption reached equilibrium within $180 \mathrm{~min}$. $(3 \mathrm{~h})$. Moreover, the change of $c_{\mathrm{t}}$ with adsorption time $t$ could be well-fitted with the pseudo-second-order model relative to the pseudo-first-order model, which was supported by the higher adjusted correlation coefficient of 0.993 (Table 2). The pseudo-second-order reaction rate constant was $0.22 \mathrm{~g} /(\mathrm{mg} \bullet \mathrm{min}$.$) .$
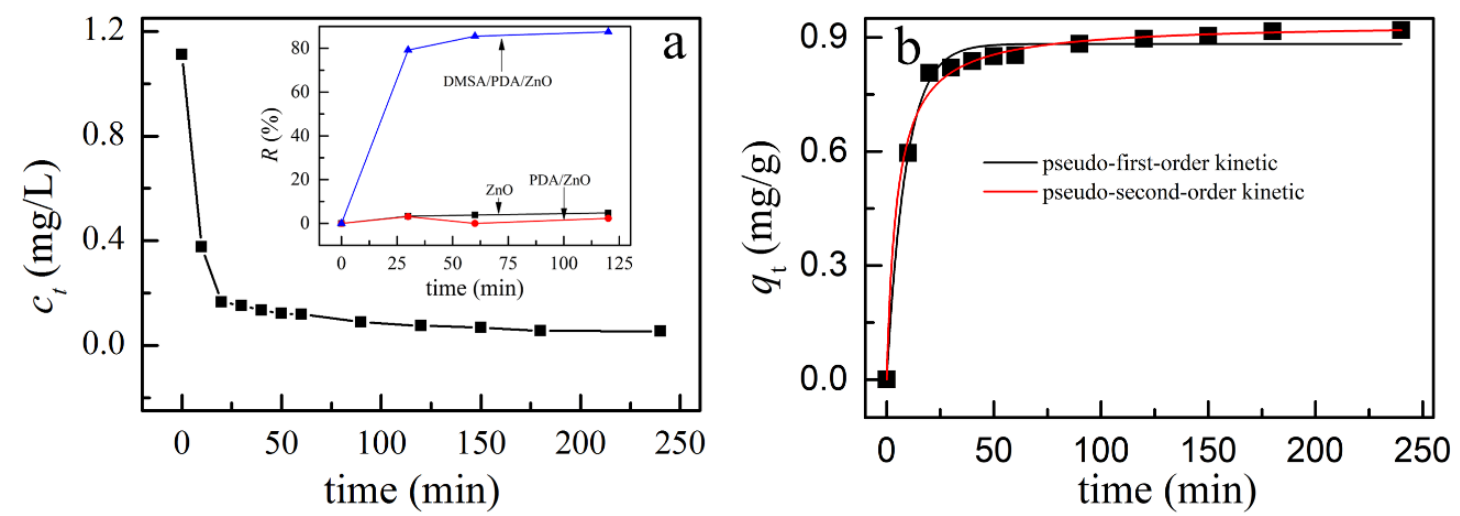

Figure 5. (a) Dependence of $\mathrm{Cd}(\mathrm{II})$ bulk concentration $\left(c_{\mathrm{t}}\right)$ on contact time, inset shows the adsorption ratio of $\mathrm{Cd}(\mathrm{II})$ on $\mathrm{ZnO}, \mathrm{PDA} / \mathrm{ZnO}$, and DMSA/PDA/ZnO; and, (b) the data fitted to the pseudo-first-order and pseudo-second-order kinetic model.

Table 2. Results for the fit of adsorption kinetics and adsorption isotherm.

\begin{tabular}{|c|c|c|c|c|c|c|c|c|}
\hline \multirow{2}{*}{ Model } & \multicolumn{4}{|c|}{ Kinetics } & \multicolumn{4}{|c|}{ Isotherm } \\
\hline & \multicolumn{2}{|c|}{ Pseudo-First-Order } & \multicolumn{2}{|c|}{ Pseudo-Second-Order } & \multicolumn{2}{|c|}{ Langmuir } & \multicolumn{2}{|c|}{ Freundlich } \\
\hline parameters & $k_{1}$ & $c_{\mathrm{e}}$ & $k_{2}$ & $c_{\mathrm{e}}$ & $K_{L}$ & $q_{\max }$ & $K_{\mathrm{F}}$ & $1 / n$ \\
\hline value & 0.11 & 0.88 & 0.22 & 0.94 & 0.14 & 28.5 & 4.55 & 0.55 \\
\hline correlation coefficient & \multicolumn{2}{|c|}{0.989} & \multicolumn{2}{|c|}{0.993} & \multicolumn{2}{|c|}{0.997} & \multicolumn{2}{|c|}{0.961} \\
\hline
\end{tabular}


The adsorption of $\mathrm{Cd}$ (II) to DMSA/PDA/ZnO could be better fitted by the Langmuir isotherm model relative to Freundlich isotherm model, as listed in Table 2. The Langmuir isotherm is an empirical model that assumes monolayer adsorption, namely, that each adsorbate exhibits constant enthalpies and sorption activation energy [32]. The adsorption of Cd(II) on DMSA/PDA/ZnO followed the Langmuir adsorption isotherm model, as shown in Figure 6 . The adsorption capacity $\left(q_{\max }\right)$ and adsorption constant $\left(K_{\mathrm{L}}\right)$ were $28.5 \mathrm{mg} / \mathrm{g}$ and $0.14 \mathrm{~L} / \mathrm{mg}$, respectively. When comparing $q_{\max }$ reported in this study with the reported values for other adsorbents $(4-137 \mathrm{mg} / \mathrm{g})$ [22], $q_{\max }$ reported in this study is in the medium rank. However, other adsorbents, like meso silica (MCM-48, SBA-15 etc.), could not be directly dissolved in acid solution.

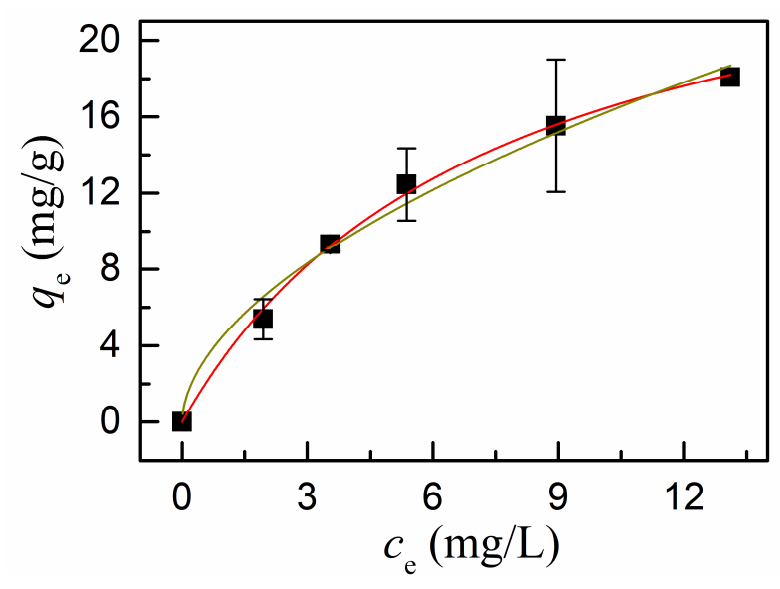

Figure 6. Dependence of the adsorbed Cd(II) per gram adsorbent $\left(q_{\mathrm{e}}\right)$ on the equilibrium concentration $\left(c_{\mathrm{e}}\right)$. The solid lines correspond to the fitting of the data to Langmuir (red line) and Freundlich (dark green line) isotherm model.

\subsection{Effects of Solution $\mathrm{pH}$ and Adsorbent Dosage on Adsorption of $\mathrm{Cd}$ on DMSA/PDA/ZnO}

Aquatic $\mathrm{pH}$ could change the distribution of adsorbate and the surface charge of adsorbent (Figure S2), which could subsequently influence the adsorption efficiency. The surface of DMSA/PDA/ZnO was negatively charged after modification by DMSA and PDA (Figure S3). The results are in line with the report that PDA is a negative polyelectrolyte [33]. The negative surface of DMSA/PDA/ZnO favored the binding of positive charged $\mathrm{Cd}$ (II) other than metal-ligand chelation. As shown in Figure 7a, aquatic $\mathrm{pH}$ had a significant influence on the adsorption of $\mathrm{Cd}(\mathrm{II})$ on DMSA/PDA/ZnO. The adsorption ratio increased from $70 \%$ to $98 \%$ for a $\mathrm{pH}$ increase from 3.0 to 7.0 and decreased to $80 \%$ at $\mathrm{pH} 9.0$. The decrease in the adsorption ratio at $\mathrm{pH} 9.0$ might also be due to the formation of $\mathrm{CdOH}^{+}$ion.
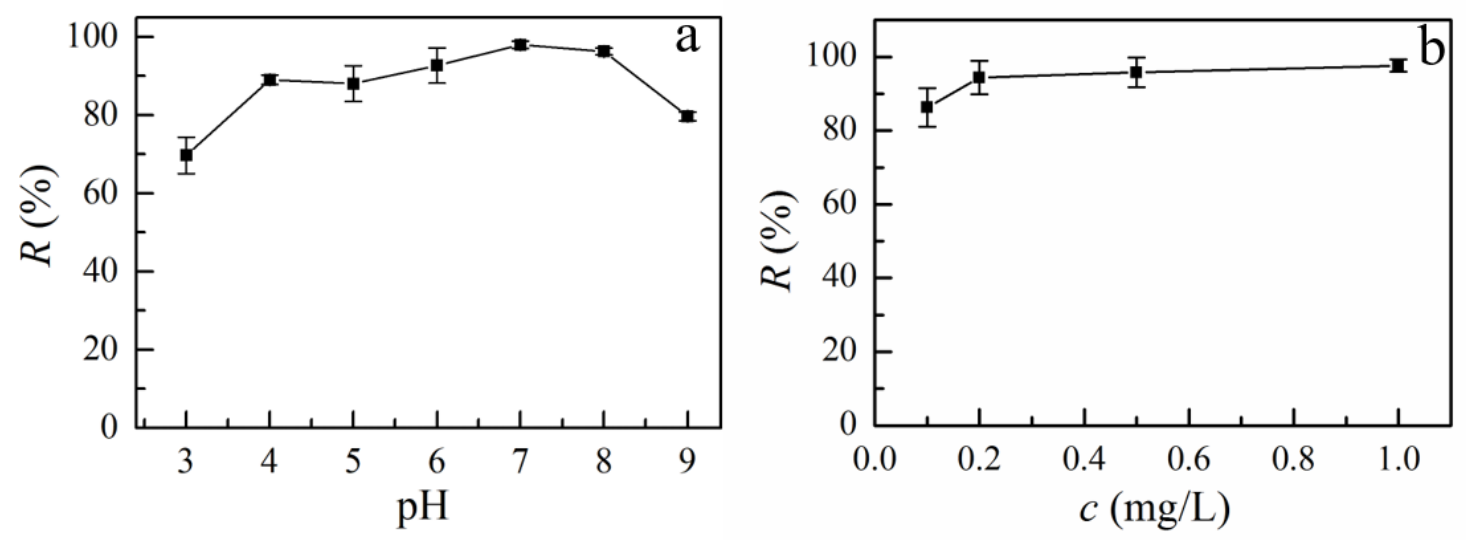

Figure 7. Effects of (a) solution $\mathrm{pH}$, and (b) DMSA/PDA/ZnO on the adsorption ratio of Cd(II). 
Figure $7 \mathrm{~b}$ shows the effects of DMSA/PDA/ZnO dosage on the adsorption of $\mathrm{Cd}$. The adsorption ratio of $\mathrm{Cd}$ increased from $86 \%$ to $94 \%$ with the increase of loaded DMSA/PDA/ZnO from 0.1 to $0.2 \mathrm{~g} / \mathrm{L}$. The adsorption ratio further increased to $98 \%$ with a further increase in DMSA/PDA/ZnO up to 1.0 $\mathrm{g} / \mathrm{L}$. The increase in adsorption rate with the increase of loaded DMSA/PDA/ZnO was likely to have been caused by the additional chelating sites for $\mathrm{Cd}(\mathrm{II})$. Therefore, a dosage of $0.5 \mathrm{~g} / \mathrm{L}$ was adopted for $\mathrm{Cd}$ (II) preconcentration due to the accepted adsorption ratio and the relatively low consumption of acid for dissolution.

\subsection{Performance of DMSA/PDA/ZnO in the Analysis of Ultra-Trace Cd(II)}

\subsubsection{Linear Region}

The linear region for the calibration curves was decided to reveal the dissolved DMSA/PDA/ZnO for the analysis of $\mathrm{Cd}$ (II) by FAAS. The dissolved matrix of DMSA, PDA, and ZnO did not influence the absorbance of $\mathrm{Cd}$ solution, as shown in Figure 8. However, the response of absorbance bent towards the $X$-axis when the concentration of $\mathrm{Cd}$ was higher than $2.0 \mathrm{mg} / \mathrm{L}$. Therefore, the calibration curve for $\mathrm{Cd}$ was from $0-2.0 \mathrm{mg} / \mathrm{L}$ (insert Figure 8).

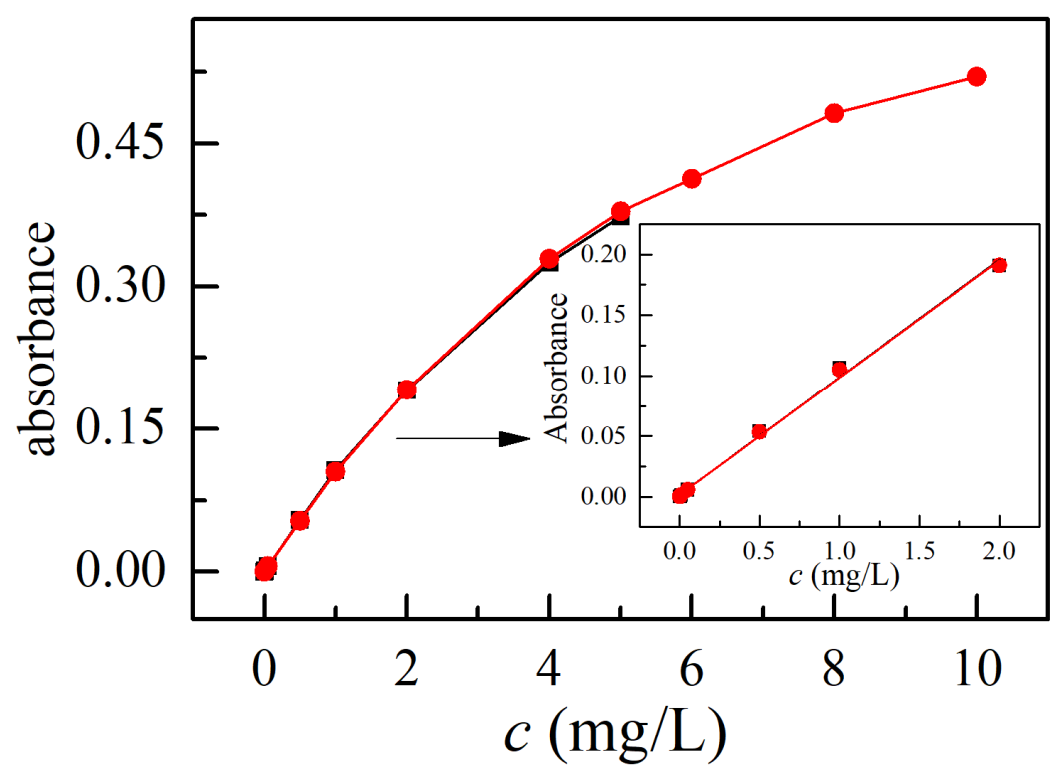

Figure 8. Calibration curves for the analysis of $\mathrm{Cd}(\mathrm{II})$ in the absence (black square) and the presence of dissolved DMSA/PDA/ZnO (red circles); inset shows the linear concentration region.

\subsubsection{Accuracy of the Method}

An environmental reference material (GBS07-1185-2000) with a Cd(II) concentration of $0.298 \pm$ $0.01 \mathrm{mg} / \mathrm{L}$ was analyzed. The environmental reference material was diluted by a factor of 20 . The reference material solution after dilution was determined by the experimental procedure that is shown in Section 2.5. The obtained Cd(II) concentration was $0.289 \pm 0.004 \mathrm{mg} / \mathrm{L}$, which was in good agreement with the certified value. The $T$-test results indicated that the analyzed value was not statistically significantly different from the certified value.

\subsubsection{Limit of Detection}

A $0.010 \mathrm{mg} / \mathrm{L} \mathrm{Cd}$ (II) solution was enriched 20 times, according to Section 2.5, and then subjected to FAAS. The limit of detection (LOD) and the relative standard deviation (RSD, $n=6$ ) of Cd were $0.1 \mu \mathrm{g} / \mathrm{L}$ and $1.0 \%$ with a preconcentration factor of 10 , respectively. The LOD that was obtained in this study was the same as that reported by using resin for preconcentration [14], both are one 
magnitude smaller than the value obtained by using amino-functionalized mesoporous sorbent for Cd(II) preconcentration [22].

\subsection{Analysis of Cd(II) in Natural Water Samples}

The above-mentioned method was used for the analysis of $\mathrm{Cd}(\mathrm{II})$ in lake and river water samples. Table 3 lists the results. The concentration of Cd in lake water was $0.6 \mu \mathrm{g} / \mathrm{L}$ and the $\mathrm{Cd}(\mathrm{II})$ concentration in the Yangtze River was below the LOD. The recoveries were $86 \%$ and $90 \%$, respectively.

Table 3. Determination of Cd(II) in water samples (sample volume: $100 \mathrm{~mL}$, final volume: $10 \mathrm{~mL}, n=3$ ).

\begin{tabular}{cccc}
\hline Sample & Added $(\mu \mathrm{g} / \mathrm{L})$ & Found $(\mu \mathrm{g} / \mathrm{L})$ & Recovery $\%$ \\
\hline Xinghu Lake & 0 & $0.6 \pm 0.02$ & - \\
& 5.0 & $4.9 \pm 0.04$ & 86 \\
Yangtze River & 0 & N.D. & - \\
& 2.0 & $1.8 \pm 0.05$ & 90 \\
\hline
\end{tabular}

\section{Conclusions}

The innovation of this study was the synthesis of DMPA/PDA/ZnO and its application in the removal and preconcentration of Cd(II). DMPA/PDA/ZnO has high adsorption capacity $(28.5 \mathrm{mg} / \mathrm{g})$ to $\mathrm{Cd}(\mathrm{II})$, because the DMPA layer was capable of chelating $\mathrm{Cd}(\mathrm{II})$, and the adsorption of $\mathrm{Cd}(\mathrm{II})$ to DMPA/PDA/ZnO followed the pseudo-second-order kinetic model. The pre-concentrated Cd(II) on DMPA/PDA/ZnO can be dissolved in $5 \% \mathrm{HCl}$, which omitted the desorption process. The dissolved solution can be directly used for FAAS analysis. The results suggested that this method has many advantages, such as a simple preconcentration process (without desorption), low detection limit, and good precision. The detection limit was low $(0.1 \mu \mathrm{g} / \mathrm{L})$, and the proposed method can be applied to determine ultra-trace $\mathrm{Cd}(\mathrm{II})$ in environmental water samples with highly satisfactory results.

Supplementary Materials: The following are available online at http://www.mdpi.com/2076-3417/10/7/2462/s1, Figure S1: Statistical analysis of ZnO size from TEM image, Figure S2: DLS volume plot of ZnO, PDA/ZnO, and DMSA/PDA/ZnO (0.1 g/L), Figure S3: Surface zeta potential $(\zeta)$ of ZnO and DMSA/PDA/ZnO (0.1 g/L).

Author Contributions: Investigation, Data Curation M.L.; Water Sampling, Data Curation N.C.; and Conceptualization, Writing-Review and Editing, X.Z. All authors have read and agreed to the published version of the manuscript.

Funding: This research was funded by the National Natural Science Foundation of China (Grant No. 21477091).

Conflicts of Interest: The authors declare no conflict of interest.

\section{References}

1. Canton, J.H.; Slooff, W. Toxicity and accumulation studies of cadmium $\left(\mathrm{Cd}^{2+}\right)$ with freshwater organisms of different trophic levels. Ecotox. Environ. Safe. 1982, 6, 113-128. [CrossRef]

2. Yu, Z.; Wei, H.; Hao, R.; Chu, H.; Zhu, Y. Physiological changes in chlamydomonas reinhardtii after 1000 generations of selection of cadmium exposure at environmentally relevant concentrations. Environ. Sci. Proc. Imp. 2018, 20, 923-933. [CrossRef] [PubMed]

3. W.H.O. Cadmium in Drinking-Water Background Document for Development of WHO Guidelines for Drinking-Water Quality; World Health Organization: Geneva, Switzerland, 2004.

4. Sun, J.; Yang, Z.; Lee, H.; Wang, L. Simultaneous speciation and determination of arsenic, chromium and cadmium in water samples by high performance liquid chromatography with inductively coupled plasma mass spectrometry. Anal. Methods 2015, 7, 2653-2658. [CrossRef]

5. Behbahani, M.; Veisi, A.; Omidi, F.; Noghrehabadi, A.; Esrafili, A.; Ebrahimi, M.H. Application of a dispersive micro-solid-phase extraction method for pre-concentration and ultra-trace determination of cadmium ions in water and biological samples. Appl. Organomet. Chem. 2018, 32, e4134. [CrossRef]

6. Ali, M.M.; Ali, M.L.; Islam, M.S.; Rahman, M.Z. Preliminary assessment of heavy metals in water and sediment of Karnaphuli River, Bangladesh. Environ. Nanotechnol. Monit. Manag. 2016, 5, 27-35. [CrossRef] 
7. Barreto, I.S.; Andrade, S.I.E.; Cunha, F.A.S.; Lima, M.B.; Araujo, M.C.U.; Almeida, L.F. A robotic magnetic nanoparticle solid phase extraction system coupled to flow-batch analyzer and GFAAS for determination of trace cadmium in edible oils without external pretreatment. Talanta 2018, 178, 384-391. [CrossRef]

8. Akkaya, E.; Aylin Kasa, N.; Çetin, G.; Bakirdere, S. A new method for the determination of cadmium at ultratrace levels using slotted quartz tube-flame atomic absorption spectrometry after preconcentration with stearic acid coated magnetite nanoparticles. J. Anal. At. Spectrom. 2017, 32, 2433-2438. [CrossRef]

9. Hideo, A.; Hiroshi, K.; Eiji, Y. Spectrophotometric determination of cadmium(II) with dithizone and 1,10-phenanthroline. Bull. Chem. Soc. Jpn. 1979, 52, 3718-3720.

10. Wen, X.; Yang, Q.; Yan, Z.; Deng, Q. Determination of cadmium and copper in water and food samples by dispersive liquid-liquid microextraction combined with UV-vis spectrophotometry. Microchem. J. 2011, 97, 249-254. [CrossRef]

11. Yilmaz, V.; Yilmaz, H.; Arslan, Z.; Leszczynski, J. Novel Imprinted polymer for the preconcentration of cadmium with determination by inductively coupled plasma mass spectrometry. Anal. Lett. 2017, 50, 482-499. [CrossRef]

12. Safari, M.; Yamini, Y.; Masoomi, M.Y.; Morsali, A.; Mani-Varnosfaderani, A. Magnetic metal-organic frameworks for the extraction of trace amounts of heavy metal ions prior to their determination by ICP-AES. Microchim. Acta. 2017, 184, 1555-1564. [CrossRef]

13. Dos Santos, W.N.L.; Costa, J.L.O.; Araujo, R.G.O.; de Jesus, D.S.; Costa, A.C.S. An on-line pre-concentration system for determination of cadmium in drinking water using FAAS. J. Hazard. Mater. 2006, 137, 1357-1361. [CrossRef]

14. Lemos, V.A.; do Nascimento, G.S.; Nunes, L.S. A new functionalized resin for preconcentration and determination of cadmium, cobalt, and nickel in sediment samples. Water Air Soil Poll. 2015, 226, 2. [CrossRef]

15. Minaberry, Y.S.; Tudino, M. An ion imprinted amino-functionalized mesoporous sorbent for the selective minicolumn preconcentration of cadmium ions and determination by GFAAS. Anal. Methods 2018, 10, 5305-5312. [CrossRef]

16. Ferreira, S.L.C.; Miró, M.; da Silva, E.G.P.; Matos, G.D.; dos Reis, P.S.; Brandao, G.C.; dos Santos, W.N.L.; Duarte, A.T.; Vale, M.G.R.; Araujo, R.G.O. Slurry Sampling-An Analytical Strategy for the Determination of Metals and Metalloids by Spectroanalytical Techniques. Appl. Spectrosc. Rev. 2010, 45, 44-62. [CrossRef]

17. Lee, H.; Dellatore, S.M.; Miller, W.M.; Messersmith, P.B. Mussel-inspired surface chemistry for multifunctional coatings. Science 2007, 318, 426-430. [CrossRef]

18. Singh, N.; Sallem, F.; Mirjolet, C.; Nury, T.; Sahoo, S.K.; Millot, N.; Kumar, R. Polydopamine modified superparamagnetic iron oxide nanoparticles as multifunctional nanocarrier for targeted prostate cancer treatment. Nanomaterials 2019, 9, 138. [CrossRef]

19. Park, J.Y.; Back, S.H.; Chang, S.-J.; Lee, S.J.; Lee, K.G.; Park, T.J. Dopamine-assisted synthesis of carbon-coated silica for PCR Enhancement. ACS Appl. Mater. Interfaces 2015, 7, 15633-15640. [CrossRef]

20. Soyekwo, F.; Zhang, Q.; Zhen, L.; Ning, L.; Zhu, A.; Liu, Q. Borate crosslinking of polydopamine grafted carbon nanotubes membranes for protein separation. Biochem. Eng. J. 2018, 337, 110-121. [CrossRef]

21. Jiang, J.; Zhu, L.; Zhu, L.; Zhu, B.; Xu, Y. Surface characteristics of a self-polymerized Dopamine coating deposited on hydrophobic Polymer Films. Langmuir 2011, 27, 14180-14187. [CrossRef]

22. Chen, Y.; Gao, J.; Wen, X.; Wu, W. Efficient removal of cadmium using facile functionalized of mesoporous silica via a biomimetic coating. RSC Adv. 2016, 6, 18340-18347. [CrossRef]

23. Song, Q.; Li, M.; Huang, L.; Wu, Q.; Zhou, Y.; Wang, Y. Bifunctional polydopamine@Fe $\mathrm{O}_{4}$ core-shell nanoparticles for electrochemical determination of lead(II) and cadmium(II). Anal. Chim. Acta 2013, 787, 64-70. [CrossRef] [PubMed]

24. Gluhcheva, Y.; Kamenova, K.; Dorkov, P.; Lobanova, Y.; Skalnaya, M.; Ivanova, J. Comparative effects of meso-2,3-dimercaptosuccinic acid, monensin and salinomycin on the concentrations of cadmium and some essential elements in skeletal muscles of Cd-exposed mice. J. Trace. Elem. Med. Biol. 2018, 50, 596-600. [CrossRef] [PubMed]

25. Kaviani, S.; Shahab, S.; Sheikhi, M.; Ahmadianarog, M. DFT study on the selective complexation of meso-2,3-dimercaptosuccinic acid with toxic metal ions $\left(\mathrm{Cd}^{2+}, \mathrm{Hg}^{2+}\right.$ and $\left.\mathrm{Pb}^{2+}\right)$ for pharmaceutical and biological applications. J. Mol. Struct. 2019, 1176, 901-907. [CrossRef] 
26. Andersen, O.; Nielsen, J.B. Oral Cadmium Chloride Intoxication in Mice: Effects of Penicillamine, Dimercaptosuccinic Acid and Related Compounds. Pharmacol. Toxicol. 1988, 63, 386-389. [CrossRef]

27. Fang, X.; Hua, F.; Fernando, Q. Comparison of rac- and meso-2,3-Dimercaptosuccinic Acids for Chelation of Mercury and Cadmium Using Chemical Speciation Models. Chem. Res. Toxicol. 1996, 9, 284-290. [CrossRef]

28. Khorsand Zak, A.; Abd. Majid, W.H.; Abrishami, M.E.; Yousefi, R. X-ray analysis of ZnO nanoparticles by Williamson-Hall and size-strain plot methods. Solid State Sci. 2011, 13, 251-256. [CrossRef]

29. Wang, Z.; Zhang, H.; Zhang, L.; Yuan, J.; Yan, S.; Wang, C. Low-temperature synthesis of ZnO nanoparticles by solid-state pyrolytic reaction. Nanotechnology 2002, 14, 11-15. [CrossRef]

30. Luo, H.; Gu, C.; Zheng, W.; Dai, F.; Wang, X.; Zheng, Z. Facile synthesis of novel size-controlled antibacterial hybrid spheres using silver nanoparticles loaded with poly-dopamine spheres. RSC Adv. 2015, 5, 13470-13477. [CrossRef]

31. Wang, K.; Fu, J.; Wang, S.; Gao, M.; Zhu, J.; Wang, Z.; Xu, Q. Polydopamine-coated magnetic nanochains as efficient dye adsorbent with good recyclability and magnetic separability. J. Colloid. Interface Sci. 2018, 516, 263-273. [CrossRef]

32. Kundu, S.; Gupta, A.K. Arsenic adsorption onto iron oxide-coated cement (IOCC): Regression analysis of equilibrium data with several isotherm models and their optimization. Biochem. Eng. J. 2006, 122, 93-106. [CrossRef]

33. Zhao, L.; Bi, D.; Qi, X.; Guo, Y.; Yue, F.; Wang, X.; Han, M. Polydopamine-based surface modification of paclitaxel nanoparticles for osteosarcoma targeted therapy. Nanotechnology 2019, 30, 255101. [CrossRef] [PubMed]

(C) 2020 by the authors. Licensee MDPI, Basel, Switzerland. This article is an open access article distributed under the terms and conditions of the Creative Commons Attribution (CC BY) license (http://creativecommons.org/licenses/by/4.0/). 